\title{
Kırmızı hevhulma (Lythrum salicaria L.) bitkisinin toplam fenolik bileşik tayini ile antioksidan ve antimikrobiyel aktivitelerinin belirlenmesi
}

\author{
Determination of total phenolic compound, antioxidant and antimicrobial activities of \\ purple loosestrife (Lythrum salicaria L.) plant
}

Mehmet Soner ENGİN,a, Selin KALKAN*1,b, Mustafa Remzi OTAĞ $\breve{G}^{1, \mathrm{c}}$

${ }^{1}$ Giresun Üniversitesi, Mühendislik Fakültesi, Gıda Mühendisliği Bölümü, 28200, Giresun

$\ddot{O} z$

Kırmızı (Tıbbi) hevhulma olarak bilinen Lythrum salicaria L. ishal, kronik bağırsak nezlesi, diş eti kanamaları, hemoroid ve egzama tedavisinde kullanılmaktadır. Bu çalışmada, Lythrum salicaria L.'nin (Lythraceae) kurutulmuş çiçek-yaprak ve sap kısımları, sırasıyla etil alkol (\%80 v/v) ve asetik asit-su (1.5:98.5 v/v) gibi farklı çözücüler ile ekstrakte edilmiştir. Tüm ekstraktların toplam fenolik madde miktarları tespit edilerek antimikrobiyel ve antioksidan aktiviteleri in vitro yöntemler kullanılarak araştırılmıştır. Sonuç olarak, toplam fenolik madde miktarını belirlemede uygulanan FolinCiocalteu yöntemi sonucunda, en yüksek toplam fenolik bileşik miktarı kırmızı hevhulmanın çiçek-yaprak kısmının asetik asit-su ekstraksiyonunda olduğu saptanmış ve $5.916 \pm 0.335 \mathrm{mg}$ Gallik Asit Eşdeğeri (GAE)/g olduğu tespit edilmişsir. Serbest radikal süpürücü aktivite (1,1-difenil-2-pikrilhidrazil, DPPH•) analizi sonucunda, bitkinin çiçek-yaprak kısmının asetik asit-su ekstraksiyonunda, en yüksek radikal süpürme değeri olarak $10.697 \pm 0.155 \mathrm{mM}$ Troloks eşdeğeri (TE) $/ \mathrm{g}$ Kuru Madde (KM) bulunmuş ve ekstrakt konsantrasyonu arttıkça DPPH inhibisyonunun arttı̆̆ gözlemlenmiştir. Disk difüzyon metoduyla yapılan antimikrobiyel aktivite sonuçlarına göre, tüm ekstraktlar kıyaslandığında, bitkinin çiçekyaprak kısmının etil alkol ile elde edilmiş ektraktı ile en yüksek antimikrobiyel etkinin $25.33 \pm 0.57 \mathrm{~mm}$ zon çapı ile Proteus vulgaris'a karşı olduğu tespit edilmiştir.

Anahtar kelimeler: Antimikrobiyel aktivite, Biyoaktivite, Lythrum salicaria L., Toplam fenolik madde

\begin{abstract}
Lythrum salicaria L. known as "Kirmizl (Tibbi) hevhulma" in Turkish is used for its several beneficial health effects against diarrhea, chronic intestinal fever, gingival bleeding, hemorrhoids and eczema. In this study, dried herbal parts of Lythrum salicaria L. (Lythraceae) were sequentially extracted with different solvents such as ethyl alcohol and acetic acid-water, respectively. Total amount of phenolic substances of all extracts were determined and antioxidant and antimicrobial activities of all the extracts were investigated using in vitro methods. Consequently, because of FolinCiocalteu method applied to determine the total amount of phenolic substances, the highest total amount of phenolic compounds was determined in the acetic acid-water extract of the parts of flower-leaf of plant and it was found to be $5.916 \pm 0.335 \mathrm{mg}$ Gallic Asid Eqivalent $(G A E) / \mathrm{g}$. As a result of free radical scavenging activity (1,1-diphenyl-2picrilhydrazyl, DPPH•) analysis, $10.697 \pm 0.155 \mathrm{mM}$ Trolox equivalent (TE)/g Dry Matter (DM) was found in the acetic acid-water extract of the flower-leaf part of the plant and it was observed that DPPH inhibition increased as the extract concentration increased. According to the results of antimicrobial activity performed by the disk diffusion method, it was determined that the highest antimicrobial effect against the Proteus vulgaris with the ethanol extract of the flower-leaf part of the stem of the plant and the zone diameter was found as $25.33 \pm 0.57 \mathrm{~mm}$.
\end{abstract}

Keywords: Antimicrobial activity, Bioactivity, Lythrum salicaria L., Total phenolic compounds

\footnotetext{
*b Selin KALKAN; selin.kalkan@ giresun.edu.tr, Tel: (0454) 31017 40, orcid.org/0000-0002-4142-3152

${ }^{\mathrm{a}}$ orcid.org/0000-0001-5954-5628 $\quad{ }^{\mathrm{c}}$ orcid.org/0000-0001-5450-1546
} 


\section{Giriş}

Kırmızı hevhulma (Lythrum salicaria L.), Avrupa ve Asya'ya özgü bir bitki türüdür. Ancak günümüzde Kuzey Amerika, Kuzeybatı Afrika ve Kuzeydoğu Avustralya'da da yaygın olarak yetişmektedir. Lythraceae familyası Türkiye'de yaklaşık 12 takson ile temsil edilirken, Avrupa'da bu familya 30 takson içermektedir (Davis, 1970). Bu bitki, su kenarlarında 1400 m ye kadar yetişen, 20-180 cm boyunda, dallanmış ot veya çalılar şeklindedir. Yaprakları 10-70 mm uzunluğunda, ovalden-lanseolata doğrudur; basit, karşılıklı dizilmiş, almaşlı veya dairesel ve tüylüdür. Çiçekler tek veya bazen birleşik terminal başak durumlu ve trimorfiktir. Dik gövdesinin uç kısımlarında yer alan gül rengindeki çiçekleri Haziran-Eylül ayları arasında açar. Epikaliks genellikle bulunur. Petaller 4-6 adet ve serbesttir. Stamenler 2-12 arasındadır. Ovaryum üst durumlu, meyve kapsüldür. Tohum sayıları oldukça fazladır, fakat tohumlar endosperm içermezler. Doğal yayılış alanı olan ülkemizde bu bitki dengeli bir gelişim göstermektedir (Türe vd, 2004). Şekil 1'de çalışmamızda kullanılan Kırmızı hevhulma (Lythrum salicaria L.) bitkileri gösterilmiştir.

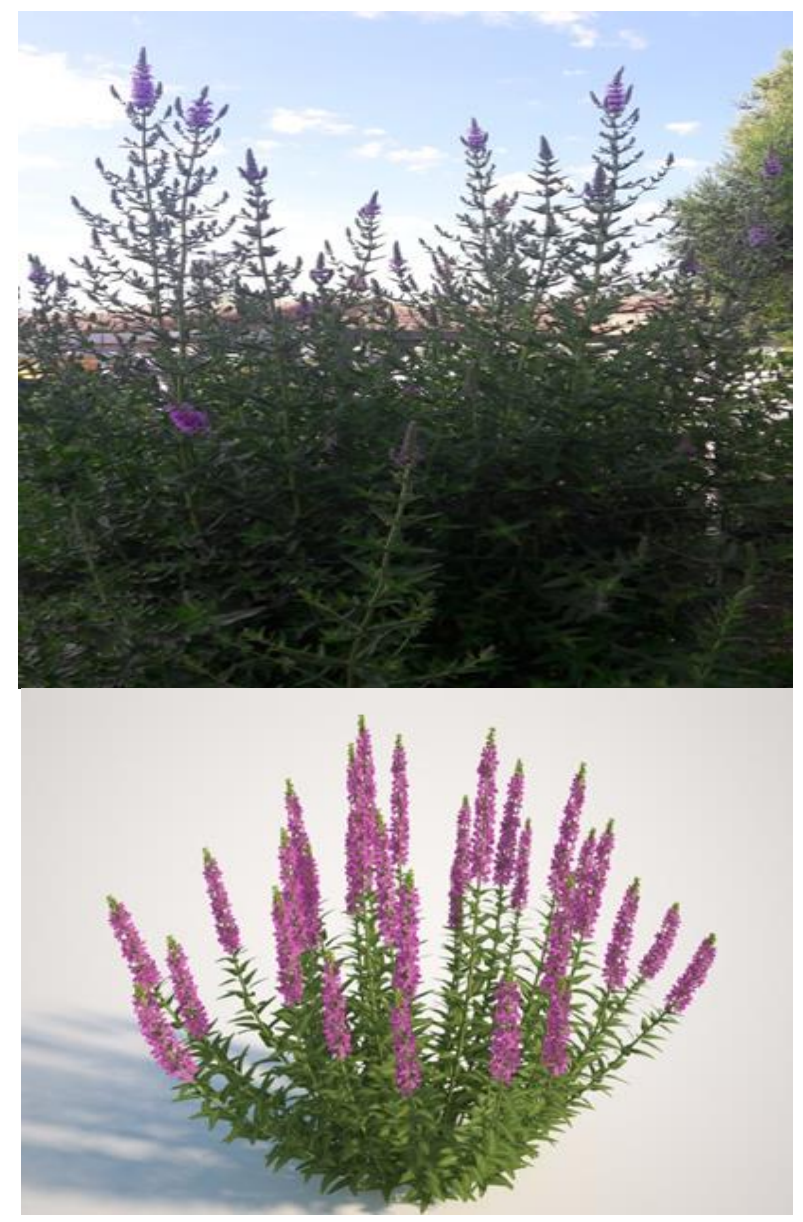

Şekil 1. Kırmızı hevhulma (Lythrum salicaria L.) bitkisinin çiçek, yaprak ve gövde kısımları
Kırmızı hevhulma (L. salicaria $\quad$ L.) eski zamanlardan beri bilinen ve sık kullanılan bir tıbbi bitkidir. Bu bitkinin kurutulmuş parçalarından elde edilen ekstraktları, geleneksel olarak ishal, kronik bağırsak nezlesi, mide ağrıları, hemoroidler, egzama, varisli damarlar ve diş eti kanamalarının tedavisinde kullanılmıştır. Günümüzde, bu bitkinin çiçekli kısmı olan Lythri herba, Ph. Hg. VIII. (Hungarian Pharmacopoeia) içerisinde yer alan resmi bir ilaçtır. Son y1llarda, etnoparmakolojik gözlemler (örn., antidiyareik veya hemostiptik etkiler) ve yeni terapötik amaçlar (örn. hiperkolesterolemi veya ateroskleroz) için bitki ekstraktlarının in vitro ve in vivo farmakolojik araştırmalarda kullanımı üzerinde durulmaktadır (Tímea, 2014). L. salicaria L. hakkında yapılan çalışmalarda, ekstraktlarının ana gruplarına, yani tanenlere ve flavonoidlere atfedilen kanamay1 durdurucu, antidiyareik, hipoglisemik, antioksidan, antienflamatuar, antinosiseptif, antifungal, antibakteriyel ve kalsiyum antagonistik özelliklere sahip olduğu bildirilmiştir (Torres ve Suarez, 1980; Lamela vd., 1985, 1986; Brun vd., 1998; Rauha vd., 1999; Kahkönen, 1999; Rauha vd., 2000; Rauha vd., 2001; Becker vd., 2005; Tunalıer vd., 2007; Tokar, 2007; Humadi ve Istudor, 2009; Møller vd., 2009; Pawlaczyk vd., 2010; Piwowarski ve Kiss, 2011).

Büyük polifenol grubuna ait olan flavonoidler tıbbi öneme sahiptir; düşük yoğunluklu lipoproteinin (LDL) oksidasyonunu engellediği, koroner kalp hastalığı riskini azalttığı, antitümör, antispazmolitik, antibakteriyel, antifungal, antienflamatuar, hepatoprotektif, östrojenik veya analjezik aktivitelere sahip oldukları bulunmuştur. Flavonoidler, bitkisel gidalarda bulunduğundan günlük diyetimizde büyük miktarda tüketilir (Harborne ve Williams 2000; Havsteen, 2002). L. salicaria'nın flavonoid bileşikleri, orientin, izoorientin, vitexin ve izovitksin, flavon-Cglikozitlerdir. Bitkide bulunan bu bileşikler, UV-B korumasından sorumludur ve diğer polifenollerle birlikte, bitkilerin hem mikrobiyal istilaya hem de böcek ve memeli otçullara karşı korunmasında tartışmasız rolleri vardır. Ayrıca, gallik asit, metilgallat, klorojenik asit, ellagik asit, vanoleik asit dilakton, izoklorojenik asit ve kafeik asit $L$. salicaria'nın tanımlanmış olan önemli fenolik bileşikleridir (Timea, 2014). L. salicaria L.'nın sahip olduğu aktif bileşenler dolasıyla antioksidan aktivite gösterdiği bilinmektedir (Lamela vd., 1986; Kahkönen vd., 1999; Mantle vd., 2000; Çoban vd., 2003). Çoban vd., (2003) yapmış oldukları çalışmada, bitkinin etil alkol ekstraktının, konsantrasyona bağlı olarak süperoksit anyon radikal temizleme etkinliğine sahip olduğunu ve 
böylelikle lipit peroksidasyonu üzerinde önleyici etki gösterdiğini tespit etmişlerdir. Diğer çalışmalarda, bitkinin sulu metil alkol ekstraktının, metilinoleatın otooksidasyonunu önlediği (Kahkönen vd., 1999) ve ABTS radikaline karş1 orta derecede bir antioksidan aktivite gösterdiği bildirilmiştir (Mantle vd., 2000).

Antibiyotik direncinin gelişimi, yeni antimikrobiyel maddelerin araştırılmasını gerektiren acil bir sorundur. Geleneksel olarak farklı bulaşıcı hastalıkları tedavi etmek için çok çeşitli tıbbi bitkiler kullanılmaktadır (Sibanda ve Okoh, 2007). Çok sayıda ikincil metabolitin (örn. tanenler, terpenoidler, alkaloidler ve flavonoidler) in vitro antimikrobiyel özelliklere sahip olduğu bulunmuştur (Cowan, 1999; Papp, 2004; Papp, 2005; Lewis ve Ausubel, 2006). Yapilan çalışmalarda, L. salicaria L. ekstraktlarının Staphylococcus aureus, Staphylococcus epidermidis, Micrococcus luteus, Bacillus cereus, Bacillus subtilis, Listeria monocytogenes, Mycobacterium smegmatis, Escherichia coli, Klebsiella pneumoniae, Proteus vulgaris, Pseudomonas aeruginosa, Citrobacter freundii, Aspergillus niger, Candida albicans, Kluyveromyces fragilis, Rhodotorula rubra ve Saccaromyces cerevisiae'e gibi önemli patojen mikroorganizmalara karşı antimikrobiyel etki gösterdiği tespit edilmiştir (Rauha vd., 2000; Çıtoğlu ve Altanlar, 2003; Dulger ve Gonuz, 2004
; Becker vd., 2005; Altanlar vd., 2006; Borchardt vd., 2008; Borchardt vd., 2009).

Literatürde Kırmızı hevhulma (L. salicaria L.) bitkisinin biyoaktif özellikleri üzerine araştırmalar bulunmasına rağmen, Türkiye'de yetiştirilen türlerine ait yapılmış sınırlı sayıda çalışma bulunmaktadır. Bu çalışmada, Konya/Türkiye'de yetiştiriciliği yapılan değerli bir tıbbi bitki olan $L$. salicaria L.' 'n çiçek-yaprak ve sap kısımlarının etil alkol ve asetik asit-su ekstraktlarının toplam fenolik madde miktarlarının tespiti ile antimikrobiyel ve antioksidan özelliklerinin belirlenmesi amaçlanmıştır.

\section{Materyal ve metot}

\subsection{Materyal}

Çalı̧̧mada kullanılan Kırmızı hevhulma ( $L$. salicaria L.) bitkisi Başhüyük Mahallesi/ Sarayönü İlçesi/Konya, Türkiye'den Eylül-Ekim aylarında toplanarak, uygun koşullar altında laboratuvara getirilmiştir. Kırmızı hevhulma (L. salicaria L.) bitkisinin gövdesinden çiçek-yaprak ve sap kısımları ayrılarak, öğütücüde (Waring Blender 7011HS, Osaka Chemical Co. Ltd., Japan) toz haline getirilmiştir. Şekil 2'de Kırmızı hevhulma $(L$. salicaria L.) bitkisinin toplanma alanı gösterilmiştir.

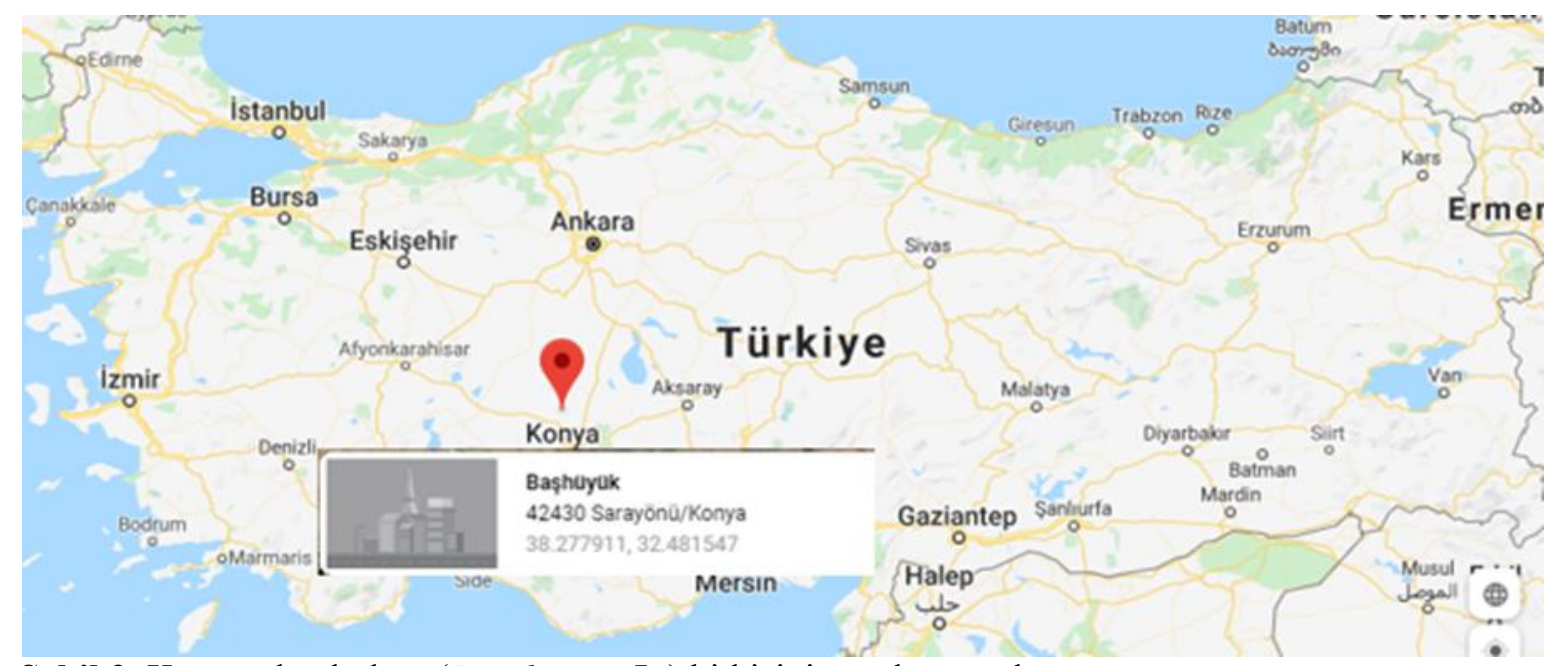

Şekil 2. Kırmızı hevhulma (L. salicaria L.) bitkisinin toplanma alanı

Çalışmada kullanılan Gram pozitif (Listeria monocytogenes, Staphylococcus epidermis (ATCC 12228), Staphylococcus aureus (ATCC 25923), Bacillus cereus, Enterococcus faecalis (ATCC 29212)) ve Gram negatif bakteriler (Escherichia coli Type 1, Vibrio parahaemolyticus (ATCC 17802), Salmonella typhimurium (ATCC 14028), Yersinia pseudotuberculosis (ATCC 911), Klebsiella pneumoniae (ATCC 700603), Proteus vulgaris (ATCC 13315)) ile önemli küf türlerinden olan Aspergillus niger ve patojenik özellik gösteren maya türü olan Candida albicans suşları Giresun Üniversitesi Gıda Mühendisliği Bölümü kültür koleksiyonundan temin edilmiştir.Kültürlerin 0.5 McFarland skalası esas alınarak mililitresinde $1.5 \times 10^{6}(\mathrm{KOB} / \mathrm{mL})$ hücre olacak şekilde bakteri ve küf-maya stok solüsyonları hazırlanmıştır (Engin vd., 2019). 


\subsection{Kırmızı hevhulma (L. salicaria 1.) bitkisinin ektraksiyonu}

Ekstraksiyon için öncelikle bitkinin çiçek-yaprak kısmı, ardından gövde (sap) kısmı hazırlanmıştır. $40{ }^{\circ} \mathrm{C}$ 'de kurutulan bu kısımlar, çiçek-yaprak ve sap kısmı olmak üzere 2 farklı gruba ayrılarak, 2 farklı çözgen kullanılarak ekstrakte edilmiştir. $\mathrm{Bu}$ gruplar;

K1A; L. salicaria L.'nın çiçek ve yaprak kısmının asetik-asit su (1.5:98.5 v/v) ekstrakt1

K1E: L. salicaria L.'nın çiçek ve yaprak kısmının etanol $(\% 80 \mathrm{v} / \mathrm{v})$ ekstraktı

K2A: L. salicaria L.'nın sap kısımlarının asetikasit su $(1.5: 98.5 \mathrm{v} / \mathrm{v})$ ekstraktı

K2E: L. salicaria L.'nın sap kısımlarının etanol $(\% 80 \mathrm{v} / \mathrm{v})$ ekstrakt1

şeklindedir. Çiçek-yaprak ile sap örneklerinden 5'er gr alınıp $100 \mathrm{~mL}$ asetik asit-su karışımı $(1.5: 98.5)$ ve $100 \mathrm{~mL}(\% 80 \mathrm{v} / \mathrm{v})$ etil alkol içinde 24 saat boyunca, oda sıcaklığında çalkalamalı karıștırıcıda iyice karıștırılarak, filtre kağıdından (Whatman filter paper No.1) geçirilmiş ve süzülmüştür. Süzme işleminden sonra geriye kalan posalara çözgenler yeniden eklenip ikinci kez 24 saat karışmaya bırakılmıştır. Süzülen ekstraktlar ağzı şilifli erlenlere alınıp rotary evaparatöre bağlatılıp çözgenlerin uçurulmaları sağlanmıştır. Daha sonra örnekler analizlerde kullanılmak üzere buzdolabında $+4{ }^{\circ} \mathrm{C}$ 'de depolanmıştır (Engin vd., 2019).

\subsection{Toplam fenolik madde tayini}

Bitki özütlerindeki çözünebilen toplam fenolik madde içeriği Folin-Ciocalteu ayıracı kullanılarak belirlenmiştir. $0.25 \mathrm{~mL}$ ekstrakt içeren $100 \mathrm{~mL}$ ' lik balon jojelerin içine $1.25 \mathrm{~mL}$ Folin-Ciocalteu ayıracı ve $2.5 \mathrm{~mL} \mathrm{NaHCO}_{3} \quad(\% 7.5)$ çözeltisi eklenerek $45^{\circ} \mathrm{C}$ 'de 45 dakika su banyosunda inkübe edilmiştir. İnkübasyon sonrası numuneler, alüminyum folyoya sarılıp 1 saat karanlık ortamda beklemeye bırakılmıştır. Karışımların absorbansı $720 \mathrm{~nm}$ 'de spektrofotometrik olarak ölçülmüştür. Standart olarak gallik asidin kullanıldı $\breve{g}_{1}$ kalibrasyon grafiğine göre, toplam fenolik içerik gram başına mg gallik asit eşdeğerleri (mg GAE/g) olarak ifade edilmiştir (Türkmen vd., 2019).

\subsection{Antioksidan aktivite tayini}

Ekstraktların serbest radikalleri giderme etkinliği olarak ifade edilen antioksidan aktiviteleri, DPPH (2,2- diphenyl 1-picrylhydrazyl) radikali kullanılarak belirlenmiştir. Ekstraktlar, sırayla 20 $\mu \mathrm{L}, 40 \mu \mathrm{L}, 60 \mu \mathrm{L}, 80 \mu \mathrm{L}, 100 \mu \mathrm{L}$ olarak tüplere aktarılmış ve $3.9 \mathrm{~mL}$ metanol içerisinde hazırlanmış DPPH radikali $(0.025 \mathrm{~g} / \mathrm{L}) 600 \mu \mathrm{L}$ olarak eklenmiştir. Tüpler vorteks cihazında karıştırılmış ve yaklaşık 30 dakika karanlık bir ortamda inkübasyona bırakılmıştır. İnkübasyon sonras1, spektrofotometrede $517 \mathrm{~nm}$ dalga boyunda tüplerin içerisindekilerin absorban değerleri okunmuştur. Kör için elde edilen absorbans değeri dikkate alınarak yapılan hesaplama ile yüzde inhibisyon değerleri belirlenmiştir (BrandWilliams vd., 1995). \% olarak belirlenen DPPH inhibisyonu aşağıdaki formüle göre hesaplanmıştır.

$\%$ İnhibisyon $=\left[\left(\mathrm{A}_{\text {kontrol }}-\mathrm{A}_{\text {örnek }}\right) / \mathrm{A}_{\text {kontrol }}\right] \times 100$

\subsection{Antimikrobiyel aktivite tayini}

Kırmızı hevhulma (L. salicaria L.) bitki ekstraktlarının patojen mikroorganizmalara karşı antimikrobiyel aktiviteleri, disk difüzyon yöntemi kullanılarak, in vitro olarak, Klinik Laboratuvar Standartları Enstitüsü standartlarına göre belirlenmiştir. Disk difüzyon testi için; Elde edilen kuru ve / veya mumsu bitki ekstreleri dimetil sülfoksit (\% 10; DMSO) içerisinde 1:1 oranında çözülmüsşür. $10^{6} \mathrm{KOB} / \mathrm{mL}$ bakteri hücresi $100 \mu \mathrm{L}$ olarak Mueller Hinton Agar (Merck) besiyerlerine ekimleri gerçekleştirilmiş, $30 \mathrm{dk}$ kurumaya bırakılmıştır. Steril forseps kullanarak, 10, 20 ve 30 $\mu \mathrm{L}$ bitki ekstreleri içeren steril filtre kağıtları (6 mm çap) ve negatif kontrol (\% 10 DMSO) test mikroorganizmaları ile sürme ekimleri yapılmış agarlı besiyeri yüzeyine yerleştirilmiştir. Besiyerleri, bakteriler için 24 saat $37^{\circ} \mathrm{C}$ 'de, maya ve küfler için 72 saat $25{ }^{\circ} \mathrm{C}^{\prime}$ de inkübasyona bırakılmıştır. İnkübasyondan sonra, inhibisyon bölgesi zon çapı ölçümü yapılmıştır. Her bir deney 3 tekerrürlü olarak gerçekleştirilmiş, her bakteri ve maya-küf kültürü için antimikrobiyel aktiviteye kıyasla bir ortalama değer elde edilmiştir (Engin vd., 2019).

\section{6. İstatistiksel analizler}

Örneklerin analiz sonuçları tesadüf blokları deneme planına göre Windows SPPS 20.0 software istatistik paket programı (SPSS Inc., Chiago, IL, USA) kullanılarak yorumlanmıştır. Araştırma sonuçları tek yönlü varyans analizi (ANOVA) kullanılarak değerlendirilmiş ve önemli bulunan ortalamalar $p<0.05$ düzeyinde Duncan çoklu karşılaştırma testine göre belirlenmiştir. 


\section{Bulgular ve tartışma}

\subsection{Toplam fenolik madde miktarl}

Fenolik bileşikler, bitkinin gösterdiği antioksidan aktivitede önemli bir belirleyici grup olmalarından dolay1, örneklere ilk aşamada toplam fenolik madde analizleri yapılmıştır. Fenoller yapısal olarak, sahip oldukları fonksiyonel grupların etkinliğinden dolayı, elektron ve hidrojen verebilirler. $\mathrm{Bu}$ durum radikallerin ve oksitleyici grupların eliminasyonunu sağlar. Fenolik gruplar $\mathrm{OH}$ (hidroksil) grubunca zengindir, bu gruplar bileşiğe polar olma özelliği kazandırır ve antioksidan özelliğini artırır (Uğuzlar, 2009). Farklı ekstraktlardan elde edilen toplam fenolik madde miktarına ait sonuçlar Tablo 1'te gösterilmiştir.

Tablo 1. Kırmızı hevhulma (L. salicaria L.) bitkisinin farklı çözgenlerle elde edilmiş ekstraktlarının fenolik aktiviteleri

\begin{tabular}{cc}
\hline Örnekler* $^{*}$ & $\begin{array}{c}\text { Toplam Fenolik Aktiviteleri } \\
(\mathbf{m g} \text { GAE/g) }\end{array}$ \\
\hline K1E & $4.688 \pm 0.03^{\mathrm{c}}$ \\
K1A & $5.916 \pm 0.33^{\mathrm{d}}$ \\
K2E & $4.019 \pm 0.02^{\mathrm{b}}$ \\
K2A & $3.758 \pm 0.01^{\mathrm{a}}$ \\
\hline
\end{tabular}

*K1A: L. salicaria'nın çiçek ve yaprak kısmının asetik-asit su ekstraktı; * K1E: L. salicaria'nın çiçek ve yaprak kısmının etanol ekstraktı; K2A: L. salicaria'nın sap kısımlarının asetik-asit su ekstraktı; *. K2E: L. salicaria'nın sap kısımlarının etanol ekstraktı. Ortalama ve Std. hata; a-d: aynı harflerle gösterilen değerler istatiksel olarak önemli değildir $(p<0.05)$

Tablo 1'de de görüldüğg̈ gibi en yüksek fenolik madde miktarı $5.916 \mathrm{mg}$ GAE/g olarak bitki yaprak-çiçek kısmının asetik asit ekstraktı ile elde edilmişken, en düşük fenolik madde miktarı ise bitki gövde kısmının asetik asit-su ekstraktı ile $3.758 \pm 0.011 \mathrm{mg}$ GAE$/ \mathrm{g}$ olarak elde edilmiştir. Tunalier vd. (2007) tarafindan yapilan benzer bir çalışmada L. salicaria 'dan ekstrakte edilebilir bileşenlerin miktarı $10.32 \mathrm{mg} / \mathrm{g}$ (etil asetat ekstraktı) ile $261.35 \mathrm{mg} / \mathrm{g}$ (su ekstraktı) arasında bulunmuştur. Aynı çalışmada L. salicaria L.'nın metil alkol ekstraktı ile sulu metil alkol ekstraktlarından elde edilen toplam fenolik madde miktarının $191.35 \pm 0.45$ ile $525.76 \pm 0.86 \mathrm{mg}$ GAE/g KM olduğu tespit edilmiştir. Humadi ve Istudor (2009) tarafından gerçekleştirilen bir başka çalışmada ise, L. salicaria L. etil alkol ekstraktlarının toplam fenolik madde miktarlarının 9.2 -17.5 g GAE/ 100 g KM olarak değiştiği bildirilmiştir.

\subsection{Antioksidan aktivite}

Antioksidanlar, lipit peroksidasyonunu yavaşlatan veya başlamasını geciktiren kimyasal bileşiklerdir. Gıdaların raf ömrünü korumanın yanı sıra serbest radikallerin olumsuz etkilerine karşı vücudun savunma mekanizmasına yardımcı olmaları nedeniyle de sağlık açısından da büyük önem arz etmektedir. Bu nedenle çalıșmamızda Kırmızı hevhulma ( $L$. salicaria L.) bitkisinin farklı çözgenlerle elde edilmiş ekstraktları antioksidan aktiviteleri için test edilmiştir. Kırmızı hevhulma (L. salicaria L.) bitkisinin farklı çözgenlerle elde edilmiş ektraktlarının DPPH radikali giderme aktiviteleri Troloks eşdeğeri olarak hesaplanarak Tablo 2'de gösterilmiştir.

Tablo 2. Kırmizı hevhulma (L. salicaria L.) bitkisinin farklı çözgenlerle elde edilmiş ektraktlarının DPPH radikali giderme aktiviteleri

\begin{tabular}{cc}
\hline Örnekler* $^{*}$ & $\begin{array}{c}\text { DPPH } \\
\text { (mM Troloks eşdeğeri/g KM) }\end{array}$ \\
\hline K1A & $10.697 \pm 0.155^{\mathrm{a}}$ \\
K1E & $8.612 \pm 0.087^{\mathrm{b}}$ \\
K2A & $7.078 \pm 0.097^{\mathrm{d}}$ \\
K2E & $7.383 \pm 0.072^{\mathrm{c}}$ \\
\hline
\end{tabular}

*K1A: L. salicaria'nın çiçek ve yaprak kısmının asetik-asit su ekstraktı; * K1E: L. salicaria'nın çiçek ve yaprak kısmının etanol ekstrakt1; K2A: L. salicaria'nın sap kısımlarının asetik-asit su ekstraktı; *. K2E: L. salicaria'nın sap kısımlarının etanol ekstraktı. Ortalama ve Std. hata; a-d: aynı harflerle gösterilen değerler istatiksel olarak önemli değildir $(p<0.05)$

Tablo 2'de de görüldüğü üzere DPPH radikali süpürme aktivitesi üzerinde güçlü inhibitör etkisi gösteren ekstraktlar, Kırmız1 hevhulma ( $L$. salicaria L.) bitkisinin çiçek-yaprak kısımlarının etil alkol (8.612 \pm 0.087$)$ ve asetik asit-su $(10.697 \pm 0.155)$ ile muamelesi sonucu elde edilmiş olan ekstraktlardır. Lee vd., (2009) tarafindan yapılan benzer bir çalışmada, L. salicaria L. bitkisinin çiçek, yaprak ve sap kısımlarının metanol ekstraktlarının DPPH süpürme aktivitesi $7.7 \pm 0.1-18.3 \pm 1.1 \quad \mu \mathrm{g} / \mathrm{mL} \quad\left(\mathrm{IC}_{50}\right) \quad$ olarak bulunmuştur. Tunalier vd. (2007) tarafindan yapılan bir başka çalışmada ise $L$. salicaria $L$. bitkisinin etil asetat, petrol eteri, metil alkol, sulu metil alkol ve su ekstraktlarının DPPH radikal süpürme aktivitesi $0.1 \pm 0.0-2.7 \pm 0.1 \mathrm{mg} / \mathrm{mL}\left(\mathrm{IC}_{50}\right)$ olarak tespit edilmiştir.

\subsection{Antimikrobiyel aktivite}

Çalışmada, asetik asit-su ve etanol ile ekstrakte edilen Kırmızı hevhulma (L. salicaria L.) bitkisinin çiçek-yaprak ve gövde kısımlarının insan ve gıda 
patojeni olduğu bilinen bazı mikroorganizmalara karşı antimikrobiyel aktiviteleri belirlenmiştir.
Ekstraktların antimikrobiyel etkileri sonucu oluşan zon çapları Tablo 3 ve Tablo 4'de gösterilmiştir.

Tablo 3. Kırmızı hevhulma (L. salicaria L.) bitkisinin çiçek-yaprak kısmının farklı çözgenlerle elde edilmiş ekstraktlarının antimikrobiyel aktiviteleri (mm)

\begin{tabular}{|c|c|c|c|c|c|c|}
\hline \multicolumn{7}{|c|}{ Zon çapları (mm) } \\
\hline \multicolumn{7}{|c|}{ Ekstraktlar } \\
\hline \multicolumn{4}{|c|}{$\mathbf{K} 1 A^{*}(\mu \mathrm{L})$} & \multicolumn{3}{|c|}{ K1E* $(\mu \mathrm{L})$} \\
\hline Mikroorganizmalar & $10 \mu \mathrm{L}$ & $20 \mu \mathrm{L}$ & $30 \mu \mathrm{L}$ & $10 \mu \mathrm{L}$ & $20 \mu \mathrm{L}$ & $30 \mu \mathrm{L}$ \\
\hline Bacillus cereus & $7.33 \pm 0.57^{\mathrm{a}}$ & $9.33 \pm 0.57^{b}$ & $11.33 \pm 0.57^{\mathrm{c}}$ & $\mathrm{D}^{\mathrm{a}}$ & $\mathrm{D}^{\mathrm{a}}$ & $\mathrm{D}^{\mathrm{a}}$ \\
\hline Escherichia coli & $10.67 \pm 1.15^{\mathrm{a}}$ & $11.67 \pm 1.15^{\mathrm{a}}$ & $12.67 \pm 0.57^{\mathrm{a}}$ & $13.67 \pm 0.57^{\mathrm{a}}$ & $17.67 \pm 0.57^{\mathrm{b}}$ & $19.67 \pm 0.57^{\mathrm{c}}$ \\
\hline Staphylococcus aureus & $10.67 \pm 0.57^{\mathrm{a}}$ & $14.33 \pm 0.57^{\mathrm{b}}$ & $17.33 \pm 0.57^{\mathrm{c}}$ & $12.33 \pm 0.57^{\mathrm{a}}$ & $15.33 \pm 0.57^{\mathrm{b}}$ & $24.67 \pm 1.52^{\mathrm{c}}$ \\
\hline Staphylococcus epidermis & $7.67 \pm 0.57^{\mathrm{a}}$ & $10.00 \pm 1.00^{\mathrm{b}}$ & $12.33 \pm 1.52^{\mathrm{c}}$ & $7.33 \pm 0.57^{\mathrm{a}}$ & $14.67 \pm 0.57^{\mathrm{b}}$ & $19.67 \pm 1.52^{\mathrm{c}}$ \\
\hline Vibrio parahemolyticus & $10.33 \pm 0.57^{\mathrm{a}}$ & $14.33 \pm 0.57^{\mathrm{b}}$ & $19.33 \pm 0.57^{\mathrm{c}}$ & $11.67 \pm 1.15^{\mathrm{a}}$ & $14.00 \pm 1.00^{\mathrm{a}}$ & $20.33 \pm 4.16^{\mathrm{b}}$ \\
\hline Yersinia pseudotuberculosis & $9.33 \pm 0.57^{\mathrm{a}}$ & $13.67 \pm 1.52^{\mathrm{b}}$ & $18.33 \pm 1.52^{\mathrm{c}}$ & $10.67 \pm 0.57^{\mathrm{a}}$ & $13.33 \pm 0.57^{\mathrm{b}}$ & $23.00 \pm 1.00^{\mathrm{c}}$ \\
\hline Listeria monocytogenes & $7.33 \pm 0.57^{\mathrm{a}}$ & $13.33 \pm 2.08^{\mathrm{b}}$ & $15.33 \pm 1.15^{\mathrm{b}}$ & $11.33 \pm 0.57^{\mathrm{a}}$ & $15.33 \pm 1.52^{\mathrm{b}}$ & $21.33 \pm 1.15^{\mathrm{c}}$ \\
\hline Enterococcus faecalis & $\mathrm{D}^{\mathrm{a}}$ & $14.67 \pm 0.57^{\mathrm{b}}$ & $16.67 \pm 0.57^{\mathrm{c}}$ & $\mathrm{D}^{\mathrm{a}}$ & $11.67 \pm 0.57^{\mathrm{b}}$ & $22.67 \pm 1.15^{\mathrm{c}}$ \\
\hline Salmonella Typhimurium & $8.67 \pm 0.57^{\mathrm{a}}$ & $10.33 \pm 0.57^{\mathrm{b}}$ & $15.67 \pm 0.57^{\mathrm{c}}$ & $7.67 \pm 0.57^{\mathrm{a}}$ & $11.33 \pm 0.57^{\mathrm{b}}$ & $17.67 \pm 0.57^{\mathrm{c}}$ \\
\hline .Klebsiella pneumoniae & $10.33 \pm 0.57^{\mathrm{a}}$ & $12.67 \pm 0.57^{\mathrm{b}}$ & $19.33 \pm 0.57^{\mathrm{c}}$ & $\mathrm{D}^{\mathrm{a}}$ & $\mathrm{D}^{\mathrm{a}}$ & $20.33 \pm 1.52^{\mathrm{b}}$ \\
\hline Proteus vulgaris & $7.67 \pm 0.57^{\mathrm{a}}$ & $10.33 \pm 0.57^{\mathrm{b}}$ & $14.67 \pm 0.57^{\mathrm{c}}$ & $14.33 \pm 0.57^{\mathrm{a}}$ & $20.67 \pm 1.15^{\mathrm{b}}$ & $25.33 \pm 0.57^{\mathrm{c}}$ \\
\hline Candida albicans & $\mathrm{D}^{\mathrm{a}}$ & $7.67 \pm 0.57^{b}$ & $10.33 \pm 1.52^{\mathrm{c}}$ & $\mathrm{D}^{\mathrm{a}}$ & $10.33 \pm 0.57^{\mathrm{b}}$ & $11.67 \pm 1.15^{\mathrm{b}}$ \\
\hline Aspergillus niger & $\mathrm{D}^{\mathrm{a}}$ & $9.33 \pm 0.57^{b}$ & $10.33 \pm 0.57^{\mathrm{c}}$ & $\mathrm{D}^{\mathrm{a}}$ & $7.33 \pm 0.57^{\mathrm{b}}$ & $13.67 \pm 1.52^{\mathrm{c}}$ \\
\hline
\end{tabular}

Tablo 4. Kırmızı hevhulma (L. salicaria L.) bitkisinin gövde kısmının farklı çözgenlerle elde edilmiş ekstraktlarının antimikrobiyel aktiviteleri $(\mathrm{mm})$

\begin{tabular}{|c|c|c|c|c|c|c|}
\hline \multicolumn{7}{|c|}{ Zon çapları (mm) } \\
\hline \multicolumn{7}{|c|}{ Ekstraktlar } \\
\hline & \multicolumn{3}{|c|}{$\mathbf{K 2} \mathbf{A}^{*}(\mu \mathrm{L})$} & \multicolumn{3}{|c|}{$\mathrm{K}^{2} \mathrm{E}^{*}(\mu \mathrm{L})$} \\
\hline Mikroorganizmalar & $10 \mu \mathrm{L}$ & $20 \mu \mathrm{L}$ & $30 \mu \mathrm{L}$ & $10 \mu \mathrm{L}$ & $20 \mu \mathrm{L}$ & $30 \mu \mathrm{L}$ \\
\hline Bacillus cereus & $10.67 \pm 0.57^{\mathrm{a}}$ & $15.00 \pm 1.00^{\mathrm{b}}$ & $19.67 \pm 1.52^{\mathrm{c}}$ & $9.67 \pm 1.52^{\mathrm{a}}$ & $11.67 \pm 0.57^{\mathrm{a}}$ & $15.33 \pm 1.15^{\mathrm{b}}$ \\
\hline Escherichia coli & $11.67 \pm 0.57^{\mathrm{a}}$ & $17.33 \pm 0.57^{\mathrm{b}}$ & $20.33 \pm 1.52^{\mathrm{c}}$ & $8.67 \pm 0.57^{\mathrm{a}}$ & $10.33 \pm 0.57^{\mathrm{b}}$ & $12.33 \pm 0.57^{\mathrm{c}}$ \\
\hline Staphylococcus aureus & $10.33 \pm 0.57^{\mathrm{a}}$ & $14.33 \pm 0.57^{\mathrm{b}}$ & $23.00 \pm 1.00^{\mathrm{c}}$ & $7.67 \pm 0.57^{\mathrm{a}}$ & $9.33 \pm 0.57^{\mathrm{b}}$ & $10.67 \pm 1.15^{\mathrm{b}}$ \\
\hline Staphylococcus epidermis & $10.00 \pm 1.00^{\mathrm{a}}$ & $16.33 \pm 0.57^{\mathrm{b}}$ & $20.00 \pm 1.00^{\mathrm{c}}$ & $12.00 \pm 2.00^{\mathrm{a}}$ & $18.00 \pm 2.00^{\mathrm{b}}$ & $23.67 \pm 1.52^{\mathrm{c}}$ \\
\hline Vibrio parahemolyticus & $14.33 \pm 1.15^{\mathrm{a}}$ & $17.00 \pm 1.00^{\mathrm{b}}$ & $23.67 \pm 1.52^{\mathrm{c}}$ & $8.67 \pm 1.15^{\mathrm{a}}$ & $11.33 \pm 1.52^{\mathrm{b}}$ & $17.33 \pm 0.57^{\mathrm{c}}$ \\
\hline Yersinia pseudotuberculosis & $12.33 \pm 0.57^{\mathrm{a}}$ & $19.67 \pm 1.52^{\mathrm{b}}$ & $24.00 \pm 2.00^{\mathrm{c}}$ & $10.67 \pm 0.57^{\mathrm{a}}$ & $12.67 \pm 0.57^{\mathrm{b}}$ & $17.33 \pm 1.15^{\mathrm{c}}$ \\
\hline Listeria monocytogenes & $7.67 \pm 0.57^{\mathrm{a}}$ & $10.67 \pm 0.57^{\mathrm{b}}$ & $12.33 \pm 0.57^{\mathrm{c}}$ & $9.33 \pm 0.57^{\mathrm{a}}$ & $11.67 \pm 0.57^{\mathrm{b}}$ & $14.33 \pm 0.57^{\mathrm{c}}$ \\
\hline Enterococcus faecalis & $9.33 \pm 0.57^{\mathrm{a}}$ & $17.67 \pm 0.57^{\mathrm{b}}$ & $21.33 \pm 0.57^{\mathrm{c}}$ & $10.33 \pm 0.57^{\mathrm{a}}$ & $11.67 \pm 0.57^{\mathrm{b}}$ & $14.67 \pm 0.57^{c}$ \\
\hline Salmonella Typhimurium & $9.33 \pm 0.57^{\mathrm{a}}$ & $11.67 \pm 0.57^{\mathrm{b}}$ & $15.67 \pm 0.57^{\mathrm{c}}$ & $8.67 \pm 0.57^{\mathrm{a}}$ & $9.67 \pm 0.57^{\mathrm{a}}$ & $11.33 \pm 0.57^{b}$ \\
\hline Klebsiella pneumoniae & $13.33 \pm 0.57^{\mathrm{a}}$ & $15.67 \pm 0.57^{\mathrm{b}}$ & $21.33 \pm 0.57^{\mathrm{c}}$ & $9.33 \pm 0.57^{\mathrm{a}}$ & $13.67 \pm 0.57^{\mathrm{b}}$ & $17.33 \pm 1.15^{\mathrm{c}}$ \\
\hline Proteus vulgaris & $7.33 \pm 0.57^{\mathrm{a}}$ & $11.33 \pm 0.57^{\mathrm{b}}$ & $15.67 \pm 0.57^{\mathrm{c}}$ & $8.67 \pm 0.57^{\mathrm{a}}$ & $11.33 \pm 1.15^{\mathrm{b}}$ & $24.33 \pm 0.57^{\mathrm{c}}$ \\
\hline Candida albicans & $\mathrm{D}^{\mathrm{a}}$ & $7.33 \pm 0.57^{\mathrm{b}}$ & $10.00 \pm 1.00^{\mathrm{c}}$ & $\mathrm{D}^{\mathrm{a}}$ & $9.33 \pm 0.57^{b}$ & $12.33 \pm 1.15^{\mathrm{c}}$ \\
\hline Aspergillus niger & $\mathrm{D}^{\mathrm{a}}$ & $10.33 \pm 0.57^{\mathrm{b}}$ & $14.33 \pm 0.57^{\mathrm{c}}$ & $7.67 \pm 0.57^{\mathrm{a}}$ & $10.33 \pm 1.52^{b}$ & $13.67 \pm 0.57^{\mathrm{c}}$ \\
\hline
\end{tabular}

*K2A: L. salicaria 'nın sap kısımlarının asetik-asit su ekstraktı; *. K2E: L. salicaria 'nın sap kısımlarının etanol ekstraktı. Ortalama ve Std. hata; her bir ekstrakt türü için (K2A ve K2E) ekstrakt konsatrasyonları (10, 20 ve $30 \mu \mathrm{L}$ ) arasında aynı satırda aynı harflerle gösterilen değerler istatiksel olarak önemli değildir $(p<0.05)$; D: Dirençli 
Disk difüzyon yöntemine göre antimikrobiyel etkinin tespitinde, $5.5-9 \mathrm{~mm}$ inhibisyon çapı çok düşük inhibisyon, 9-12 mm inhibisyon çapı düşük inhibisyon, $12-15 \mathrm{~mm}$ inhibisyon çap1 ortalama inhibisyon ve $15 \mathrm{~mm}$ ve üzeri yüksek inhibisyon olarak değerlendirilmektedir (Engin vd., 2019). Tablo 3'de görüldüğü üzere, Kırmızı hevhulma ( $L$. salicaria L.) bitkisinin çiçek-yaprak kısımlarının asetik asit-su ekstraktlarının Vibrio parahemolyticus $(19.33 \pm 0.57 \mathrm{~mm})$ ve Klebsiella pneumoniae'a $(19.33 \pm 0.57 \mathrm{~mm})$ karşı en yüksek antibakteriyel aktiviteyi gösterdiği tespit edilmişken, etil alkol ekstraktlarının ise Proteus vulgaris'a $(25.33 \pm 0.57 \mathrm{~mm})$ karş1 en yüksek antibakteriyel aktivite gösterdiği belirlenmiştir. Tablo 4'de görüldüğü üzere, Kırmızı hevhulma ( $L$. salicaria L.) bitkisinin gövde kısımlarının asetik asit-su ekstraktları en yüksek antibakteriyel etkiyi Yersinia pseudotuberculosis'e $(24.00 \pm 2.00 \mathrm{~mm})$ karşı göstermiş iken, etil alkol ekstraktları ise yine Proteus vulgaris'a $(24.33 \pm 0.57 \mathrm{~mm})$ karşı en yüksek antibakteriyel aktivite göstermiştir. Farklı bitki kısımlarının farklı çözgenlerle elde edilmiş ektraktlarının genel olarak antimikrobiyel etkileri karşılaştırıldığında ise en yüksek antimikrobiyel etkinin Kırmızı hevhulma (L. salicaria L.) bitkisinin çiçek-yaprak kısımlarının etil alkol ekstraktları ile elde edildiği gözlemlenmektedir. En düşük antimikrobiyel etkiler ise bitkinin çiçekyaprak kısımlarının asetik asit-su ekstraktları ile elde edilmiştir. Tablolarda da görüldüğü gibi tespit edilen antimikrobiyel etki, muamele edilen ekstrakt dozu ile ilişkilidir. Artan dozlarda antimikrobiyel etkinin gözlemlendiği zon çaplarında artı̧̧ gerçekleşmiştir. En yüksek antimikrobiyel etkinin tespit edildiği, etil alkol ekstraksiyonu ile elde edilen Kırmızı hevhulma (L. salicaria L.) bitkisinin çiçek-yaprak kısımlarının ekstraktlarının Proteus vulgaris'a karşı gösterdiği antimikrobiyel etki Şekil 3'de gösterilmiştir.

Çalışmada kullanılan ektraktların, C. albicans ve Aspergillus niger'e karşı düşük antimikrobiyel aktivite gösterdiği belirlenmiştir. Literatürdeki çalışmalar genel olarak, bitki ekstraktlarının antifungal özelliklerinin antibakteriyel özelliklerine kıyasla daha zayıf olduğunu göstermektedir (Ali-Shtayeh vd., 1998; Ünal, 2006). Bunun durumun, ökaryotik hücre membranındaki sterollerden kaynaklandığı ileri sürülmektedir. Antimikrobiyel maddelerin, ökaryotik maya-küf hücresini inhibe etmek için hücre membranındaki sterollere bağlanması zorunlu iken, sterol taşımayan prokaryotik bakteri hücreleri için böyle bir bağlanma gerekli değildir (Zoral ve Turgay, 2014).

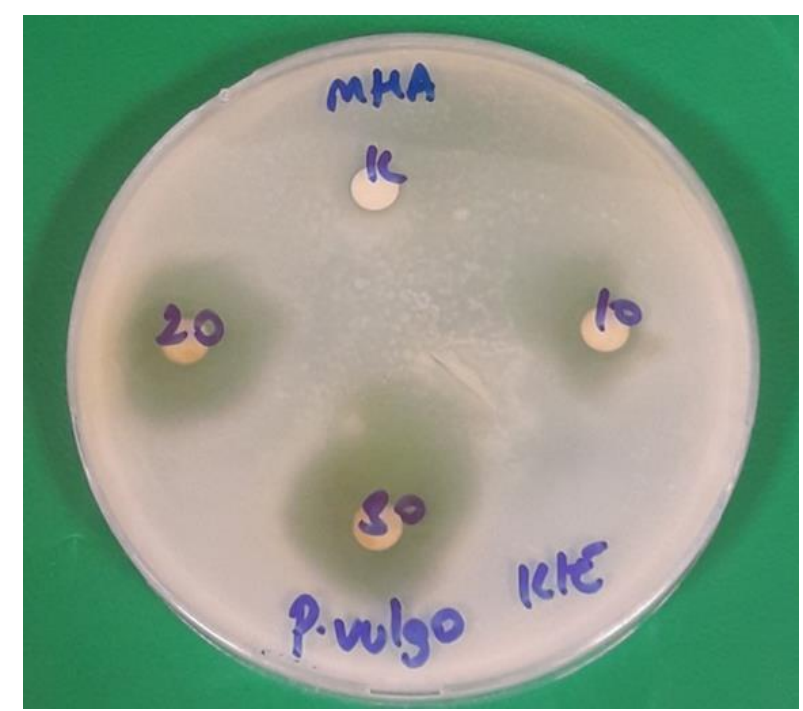

Şekil 3. Kırmızı hevhulma (L. salicaria L.) bitkisinin çiçek-yaprak kısımlarının etanol ekstraktlarının Proteus vulgaris üzerinde oluşturduğu zonlar

Çalışmamız sonuçlarına benzer olarak, Becker vd. (2005) yaptıkları çalışmada Kırmızı hevhulma ( $L$. salicaria L.) bitkisinin metil alkol ekstraktlarının $S$. aureus, $P$. mirabilis ve $M$. luteus'a karşı antimikrobiyel aktivite gösterdiğini tespit etmişlerdir. Timea, (2014) tarafindan yapılan bir başka çalışmada ise Kırmızı hevhulma (L. salicaria L.) bitkisinin sulu etil alkol ekstraktlarının Escherichia coli, Micrococcus luteus, Pseudomonas aeruginosa, Candida albicans, Staphylococcus aureus ve Staphylococcus epidermidis üzerinde aktimikrobiyel etki gösterdiği $14.0-25.5 \mathrm{~mm}$ arasında değişen zon çaplarının ölçümü ile tespit edilmiştir.

\section{Sonuçlar}

Çalışmada, Kırmızı hevhulma (L. salicaria L.) bitkisinin çiçek-yaprak ve gövde kısmının radikal giderme aktivitesi, toplam fenolik madde içeriği ve antimikrobiyel aktiviteleri belirlenmiştir. Analizler sonucunda Kırmızı hevhulmanın çiçek-yaprak kısmının asetik asit-su çözgeniyle hazırlanan ekstraktlarının, bitkinin sap kısmından elde edilen ektraktlarına kıyasla, antioksidan ve toplam fenolik madde etkisinin anlamlı bir şekilde kuvvetli olduğu belirlenmiştir. Toplam fenolik madde miktarını belirlemede uygulanan Folin-Ciocalteu yöntemi sonucunda, en yüksek toplam fenolik bileşik miktarı Kırmızı hevhulmanın çiçek-yaprak ve asetik asit-su ekstraksiyonunda olduğu saptanmış ve $5.916 .5 \pm 0.335 \mathrm{mg} \mathrm{GAE} / \mathrm{g}$ olarak tespit edilmiştir. Antioksidan aktivitesinin belirlenmesi amaciyla yapılan DPPH metodu ile radikal giderme aktivitesi belirlenmiştir. Analizler sonucunda, 
Kırmızı hevhulma bitkisinin çiçek-yaprak kısmının asetik asit-su ekstraksiyonu DPPH inhibisyon verileri en yüksek radikal süpürme değeri olarak $(10.697 \pm 0.155 \mathrm{mM}$ Troloks eşdeğeri/g KM) bulunmuş ve ekstrakt konsantrasyonu arttıkça DPPH inhibisyonu artmıştır. Antimikrobiyel aktivite için yapılan disk difüzyon yöntemiyle petrilerde görülen zon çapları ölçülerek 13 mikroorganizma üzerinde analizler yapılmıştır. Analizler sonucu, disklere ilave edilen ekstrakt konsantrasyonu artışı ile antimikrobiyel etkiyi gösteren zon çaplarında da artış görülmüştür. Antimikrobiyel aktivite sonuçlarına göre, Kırmızı hevhulma bitkisinin gövde kısmının çiçek-yaprak kısmının etil alkol ile elde edilmiş ektraktı ile en yüksek antimikrobiyel etkinin $25.33 \pm 0.57 \mathrm{~mm}$ zon çap1 ile Proteus vulgaris'a karş1 olduğu tespit edilmiştir. Çalışma sonuçları genel olarak değerlendirildiğinde, Kırmızı hevhulma bitkisinin çiçek-yaprak ve sap kısımlarının asetik asit-su ve etil alkol ekstraktlarının fenolik madde miktarı, antioksidan ve antimikrobiyel aktivitelerinin yüksek olması sebebiyle iyi bir gida koruyucu olarak değerlendirilebileceği ve elde edilen bulguların literatüre katkı sağlayarak gelecekteki çalışmalara 1ş1k tutacağı düşünülmektedir.

\section{Kaynaklar}

Ali-Shtayeh, M. S., Yaghmour, R. M. R., Faidi, Y. R., Salem, K. and Al-Nuri, M. A. (1998). Antimicrobial activity of 20 plants used in folkloric medicine in the Palestinian area. Journal of Ethnopharmacology, 60(3), 265-271. https://doi.org/10.1016/S0378-8741(97)00153-0

Altanlar, N., Saltan Çitoğlu, G. and Yılmaz, B.S. (2006). Antilisterial activity of some plants used in folk medicine. Pharmaceutical Biology, 44(2), 91-94. https://doi.org/10.1080/13880200600591907

Becker, H., Scher, J. M., Speakman, J. B. and Zapp, J. (2005). Bioactivity guided isolation of antimicrobial compounds from Lythrum salicaria. Fitoterapia, 76(6), 580-584. https://doi.org/10.1016/j.fitote.2005.04.011

Borchardt, J. R., Wyse, D. L., Sheaffer, C. C., Kauppi, K. L., Fulcher, R. G., Ehlke, N. J., Biesboer, D. D. and Bey, R. F. (2008). Antimicrobial activity of native and naturalized plants of Minnesota and Wisconsin. Journal of Medicinal Plant Research, 2(5), 98-110. https://doi.org/10.5897/JMPR.9000165

Borchardt, J. R., Wyse, D. L., Sheaffer, C. C., Kauppi, K. L., Fulcher, R. G., Ehlke, N. J., Biesboer, D. D. and Bey, R. F. (2009). Antioxidant and antimicrobial activity of seed from plants of the Mississippi river basin. Journal of Medicinal
Plant Research, 3(10), 707-718. https://doi.org/10.5897/JMPR.9000209

Brand-Williams, W., Cuvelier, M. E. and Berset, C. L. W. T. (1995). Use of a free radical method to evaluate antioxidant activity. LWT - Food Science and Technology, 28(1), 25-30.

Brun, Y., Wang, X. P., Willemot, J., Sevenet, T. and Demenge, P. (1998). Experimental study of antidiarrheal activity of Salicairine ${ }^{\circledR}$. Fundamental and Clinical Pharmacology, 12(1), 30-36. https://doi.org/10.1111/j.14728206.1998.tb00920.x

Cowan, M. M. (1999). Plant products as antimicrobial agents. Clinical Microbiology Reviews, 12(4), 564-582. https://doi.org/10.1128/CMR.12.4.564

Çıtoğlu, G. S. and Altanlar, N. (2003). Antimicrobial activity of some plants used in folk medicine. Journal of Faculty of Pharmacy of Ankara University, 32, 159-163.

Çoban, T., Çitoğlu, G. S., Sever, B. and İşcan, M. (2003). Antioxidant activities of plants used in traditional medicine in Turkey. Pharmaceutical Biology, $\quad 41(8)$, 608-613. https://doi.org/10.1080/13880200390501974

Davis, P. H. (1970). Lathyrus L. In: Davis PH (ed.) Flora of Turkey and the East Aegean Islands. (s. 328-369). Edinburgh: Edinburgh University Press.

Dulger, B. and Gonuz, A. (2004). Antimicrobial activity of certain plants used in Turkish traditional medicine. Asian Journal of Plant Sciences, 3(1), 104-107.

Engin, M. S., Kalkan, S. and Otağ, M. R. (2019). Gojiberry (Lycium barbarum L.) meyvesinin farklı çözgenlerden elde edilen ekstratlarının toplam fenolik içerikleri ile antioksidan ve antimikrobiyal aktivitelerinin karşılaştırılması. Journal of Anatolian Environmental and Animal Sciences, $\quad 4(3), \quad 359-365$. https://doi.org/10.35229/jaes.596235

Harborne, J. B. and Williams, C. A. (2000). Advances in flavonoid research since 1992. Phytochemistry, 55(6), 481-504. https://doi.org/10.1016/S0031-9422(00)00235-1

Havsteen, B. H. (2002). The biochemistry and medical significance of the flavonoids. Pharmacology and Therapeutics, 96(2-3), 67-202. https://doi.org/10.1016/S0163-7258(02)00298$\mathrm{X}$

Humadi, S. S. and Istudor, V. (2009). Lythrum salicaria (purple loosestrife). Medicinal use, extraction and identification of its total phenolic compounds. Farmacia, 57(2), 192-200. 
Kahkönen, M. P., Hopia, A. I., Vuorela, H. J., Rauha, J. P., Pihlaja, K., Kujala, T. S. and Heinonen, M. (1999). Antioxidant activity of plant extracts containing phenolic compounds. Journal of Agricultural and Food Chemistry, 47(10), 39543962. https://doi.org/10.1021/jf9901461

Lamela, M., Cadavid, I. and Calleja, J.M. (1986). Effects of Lythrum salicaria extracts on hyperglycemic rats and mice. Journal of Ethnopharmacology, 15(2), 153-160.

Lamela, M., Cadavid, I., Gato, A. and Calleja, J.M. (1985). Effects of Lythrum salicaria in normoglycemic rats. Journal of Ethnopharmacology, 14(1), 83-91.

Lee, S. E., Park, C. G., Ahn, Y. S., Son, Y. D., Cha, S. W. and Seong, N. S. (2009). Antioxidative and hepatoprotective effects of Lythrum salicaria. Korean Journal of Medicinal Crop Science, 17(1), 1-7.

Lewis, K., and Ausubel, F. M. (2006). Prospects for plant-derived antibacterials. Nature biotechnology, 24(12), 1504-1507.

Mantle, D., Eddeb, F. and Pickering, A. T. (2000). Comparison of relative antioxidant activities of British medicinal plant species in vitro. Journal of Ethnopharmacology, 72(1-2), 47-51. https://doi.org/10.1016/S0378-8741(00)00199-9

Møller, C., Hansen, S. H. and Cornett, C. (2009). Characterization of tannin-containing herbal drugs by HPLC. Phytochemical Analysis, 20(3), 231-239. https://doi.org/10.1002/pca.1119

Papp, N. (2004). Antimicrobial activity of extracts of five Hungarian Euphorbia species and some plant metabolites. Acta Botanica Hungarica, 46(3-4), 363-371. https://doi.org/10.1556/abot.46.2004.3-4.8

Papp, N. (2005). Antimicrobial activity of five Hungarian Euphorbia species. Revista de Fitoterapia, 5(2), 217.

Pawlaczyk, I., Capek, P., Czerchawski, L., Bijak, J., Lewik-Tsirigotis, M., Pliszczak-Król, A. and Gancarz, R. (2011). An anticoagulant effect and chemical characterization of Lythrum salicaria L. glycoconjugates. Carbohydrate Polymers, $86(1)$, 277-284 https://doi.org/10.1016/j.carbpol.2011.04.048

Piwowarski, J. P., Kiss, A. K. and KozłowskaWojciechowska, M. (2011). Anti-hyaluronidase and anti-elastase activity screening of tannin-rich plant materials used in traditional Polish medicine for external treatment of diseases with inflammatory background. Journal of Ethnopharmacology, 137(1), 937-941. https://doi.org/10.1016/j.jep.2011.05.039
Rauha, J. P., Remes, S., Heinonen, M., Hopia, A., Kähkönen, M., Kujala, T., Pihlaja, K., Vuorela, H. and Vuorela, P. (2000). Antimicrobial effects of Finnish plant extracts containing flavonoids and other phenolic compounds. International Journal of Food Microbiology, 56(1), 3-12. https://doi.org/10.1016/S0168-1605(00)00218$\mathrm{X}$

Rauha, J. P., Tammela, P., Summanen, J., Vuorela, P., Kähkönen, M., Heinonen, M., Hopia, A., Kujala, T., Pihlaja, K., Tornquist, K. and Vuorela, H. J. (1999). Actions of some plant extracts containing flavonoids and other phenolic compounds on calcium fluxes in clonal rat pituitary GH [sub 4] $\mathrm{C}$ [sub 1] cells. Pharmaceutical and Pharmacological Letters, 9(2), 66-69.

Rauha, J. P., Wolfender, J. L., Salminen, J. P., Pihlaja, K., Hostettmann, K. and Vuorela, H. (2001). Characterization of the polyphenolic composition of purple loosestrife (Lythrum salicaria). Zeitschrift für Naturforschung $C$, 56(1-2), 13-20. https://doi.org/10.1515/znc2001-1-203

Sibanda, T. and Okoh, A. I. (2007). The challenges of overcoming antibiotic resistance: Plant extracts as potential sources of antimicrobial and resistance modifying agents. African journal of biotechnology, 6(25), 2886-2896

Tímea, B. (2014). Comparative histological, phytochemical, microbiological and pharmacological characterization of some Lythrum salicaria L. populations. Doktora Tezi, University of Pécs, Hungary.

Tokar, M. (2007). Phytochemical analysis of purple loosestrife-Lythrum salicaria L. Herba Polonica, 53(2). 210-212

Torres, I. C. and Suarez, J. C. (1980). A preliminary study of hypoglycemic activity of Lythrum salicaria. Journal of Natural Products, 43(5), 559-563.

Tunalıer, Z., Koşar, M., Küpeli, E., Çalıș, İ. and Başer, K. H. C. (2007). Antioxidant, anti-inflammatory, anti-nociceptive activities and composition of Lythrum salicaria L. extracts. Journal of Ethnopharmacology, 110(3), 539-547. https://doi.org/10.1016/j.jep.2006.10.024

Türe, C., Bingol, N. A. and Middleton, B. A. (2004). Characterization of the habitat of Lythrum salicaria L. in floodplain forests in western Turkey-Effects on stem height and seed production. Wetlands, 24(3), 711-716. https://doi.org/10.1672/02775212(2004)024[0711:COTHOL]2.0.CO;2

Türkmen, F. U., Takçı, H. A. M., Onalan, F. E. S. and Sağlam, H. (2019). Arum dioscoridis 
ekstraktlarının toplam fenolik, flavonoid içerikleri ile antioksidan ve antibakteriyel aktivitelerinin araştırılması. Harran Üniversitesi Mühendislik Dergisi, 4(1), 102-108.

Uğuzlar, H. (2009). Antalya'da yetișen Areceae arum dioscorides tohumlarinın antioksidan aktivitesi ve toplam fenolik madde tayini. Yüksek Lisans Tezi, Selçuk Üniversitesi Fen Bilimleri Enstitüsü, Konya.
Ünal, E. (2006). Türkiye florasında doğal olarak yetişen bazl bitki türlerinin antimikrobiyel ve antioksidan aktivitelerinin incelenmesi. Yüksek Lisans Tezi, Atatürk Üniversitesi Fen Bilimleri Enstitüsü, Erzurum.

Zoral, F. B. ve Turgay, Ö. (2014). Çeşitli gıda atıklarının toplam fenolik madde içeriğinin, antioksidan ve antimikrobiyel aktivitelerinin araştırılması. $K S \ddot{U}$ Doğa Bilimleri Dergisi, 17(2), 24-33. https://doi.org/10.18016/ksujns.03907 